\title{
Forced oscillation of second-order differential equations with mixed nonlinearities
}

\author{
Yongfang Wang ${ }^{1,2}$, Tongxing $\mathrm{Li}^{1,2^{*}}$ and Ethiraju Thandapani ${ }^{3}$ \\ Dedicated to Professor Ravi P Agarwal
}

\author{
"Correspondence: \\ litongx2007@163.com \\ 1 School of Informatics, Linyi \\ University, Linyi, Shandong 276005, \\ P.R. China \\ ${ }^{2}$ LinDa Institute of Shandong \\ Provincial Key Laboratory of \\ Network Based Intelligent \\ Computing, Linyi University, Linyi, \\ Shandong 276005, P.R. China \\ Full list of author information is \\ available at the end of the article
}

\begin{abstract}
We study oscillatory behavior of a class of second-order forced differential equations with mixed nonlinearities. Some new oscillation theorems are presented that improve and complement those related results given in the literature. An example is provided to illustrate the main results.
\end{abstract}

MSC: $34 \mathrm{~K} 11$

Keywords: oscillation; forced differential equation; second-order; mixed nonlinearities

\section{Introduction}

This paper is concerned with the oscillation of solutions to a class of second-order forced differential equations with mixed nonlinearities

$$
\left(r x^{\prime}\right)^{\prime}(t)+q_{0}(t) x\left(\tau_{0}(t)\right)+\sum_{i=1}^{n} q_{i}(t)\left|x\left(\tau_{i}(t)\right)\right|^{\beta_{i}-1} x\left(\tau_{i}(t)\right)=e(t) \operatorname{sgn}(x(t))
$$

where $t \geq t_{0}>0, n \geq 1$ is a natural number, $\beta_{i} \geq 1(i=1,2, \ldots, n)$ are constants, $r \in$ $\mathrm{C}^{1}\left(\left[t_{0}, \infty\right), \mathbb{R}\right), q_{j}, \tau_{j}, e \in \mathrm{C}\left(\left[t_{0}, \infty\right), \mathbb{R}\right), r(t)>0, r^{\prime}(t) \geq 0, q_{j}(t) \geq 0(j=0,1,2, \ldots, n), e(t) \leq 0$. We also assume that there exists a function $\tau \in C^{1}\left(\left[t_{0}, \infty\right), \mathbb{R}\right)$ such that $\tau(t) \leq \tau_{j}(t)(j=$ $0,1,2, \ldots, n), \tau(t) \leq t, \lim _{t \rightarrow \infty} \tau(t)=\infty$, and $\tau^{\prime}(t)>0$.

We consider only those solutions $x$ of equation (1.1) which satisfy condition $\sup \{|x(t)|$ : $t \geq T\}>0$ for all $T \geq t_{0}$. We assume that (1.1) possesses such solutions. As usual, a solution of (1.1) is called oscillatory if it has arbitrarily large zeros on the interval $\left[t_{0}, \infty\right)$; otherwise, it is termed nonoscillatory. Equation (1.1) is said to be oscillatory if all its solutions are oscillatory.

Functional differential equations arise in many applied problems in natural sciences, technology, and automatic control; see, for instance, Hale [1]. In mechanical and engineering problems, questions related to the existence of oscillatory and nonoscillatory solutions play an important role. As a result, many theoretical studies have been undertaken during the past few years. We refer the reader to [2-12] and the references cited therein.

\section{黛 Springer}

(2014 Wang et al.; licensee Springer. This is an Open Access article distributed under the terms of the Creative Commons Attribution License (http://creativecommons.org/licenses/by/2.0), which permits unrestricted use, distribution, and reproduction in any medium, provided the original work is properly cited. 
In what follows, we briefly comment on the related results that motivate our study. $\mathrm{Li}$ and Cheng [9] studied a differential equation

$$
\left(r\left|x^{\prime}\right|^{\alpha-1} x^{\prime}\right)^{\prime}(t)+q(t)|x(t)|^{\alpha-1} x(t)=e(t) .
$$

Zheng et al. [11] considered the equation

$$
\left(r\left|x^{\prime}\right|^{\alpha-1} x^{\prime}\right)^{\prime}(t)+q_{0}(t)|x(t)|^{\alpha-1} x(t)+\sum_{i=1}^{n} q_{i}(t)|x(t)|^{\beta_{i}-1} x(t)=e(t) .
$$

Equation (1.1) was studied by Zhong et al. [12] who established the following oscillation theorem.

Theorem 1.1 (see [12, Theorem 3.1]) Assume that

$$
\int_{t_{0}}^{\infty} r^{-1}(t) \mathrm{d} t=\infty
$$

and there exists a function $\rho \in C^{1}\left(\left[t_{0}, \infty\right),(0, \infty)\right)$ such that

$$
\int_{t_{0}}^{\infty}\left(\rho(t) Q(t)-\frac{r(\tau(t))\left(\rho_{+}^{\prime}(t)\right)^{2}}{4 \rho(t) \tau^{\prime}(t)}\right) \mathrm{d} t=\infty
$$

where

$$
Q(t):=q_{0}(t)+\sum_{i=1}^{n} \beta_{i}\left[n\left(\beta_{i}-1\right)\right]^{\left(1-\beta_{i}\right) / \beta_{i}}\left(q_{i}(t)\right)^{1 / \beta_{i}}|e(t)|^{\left(\beta_{i}-1\right) / \beta_{i}}
$$

and

$$
\rho_{+}^{\prime}(t):=\max \left\{0, \rho^{\prime}(t)\right\}
$$

Then equation (1.1) is oscillatory.

The purpose of this paper is to refine Theorem 1.1 in some cases and analyze the oscillatory behavior of solutions to (1.1) in the case when the integral in (1.2) is finite. This paper proceeds as follows: in Section 2, we present our main results; in Section 3, an example is provided to illustrate the results obtained.

\section{Oscillation criteria}

In what follows, all functional inequalities are tacitly assumed to hold eventually, that is, for all $t$ large enough. Before stating the main results, we begin with the following lemma.

Lemma 2.1 (Bernoulli's inequality) For $y \geq-1$ and $\gamma \geq 1$,

$$
(1+y)^{\gamma} \geq 1+\gamma y
$$


Theorem 2.2 Assume that condition (1.2) is satisfied, and let

$$
\sum_{i=1}^{n}\left(1-\beta_{i}\right) q_{i}(t)-e(t) \geq 0
$$

If there exists a function $\rho \in \mathrm{C}^{1}\left(\left[t_{0}, \infty\right),(0, \infty)\right)$ such that, for all constants $M>0$,

$$
\begin{aligned}
\limsup _{t \rightarrow \infty} \int_{t_{0}}^{t}\left[\rho(s)\left(q_{0}(s)+\sum_{i=1}^{n} \beta_{i} q_{i}(s)+\frac{\sum_{i=1}^{n}\left(1-\beta_{i}\right) q_{i}(s)-e(s)}{M \tau(s)}\right)\right. \\
\left.-\frac{r(\tau(s))\left(\rho_{+}^{\prime}(s)\right)^{2}}{4 \rho(s) \tau^{\prime}(s)}\right] \mathrm{d} s=\infty,
\end{aligned}
$$

where $\rho_{+}^{\prime}$ is defined as in (1.4), then equation (1.1) is oscillatory.

Proof Assume that (1.1) has a nonoscillatory solution $x$. Without loss of generality, we can assume that $x$ is an eventually positive solution, i.e., there exists a $t_{1} \geq t_{0}$ such that $x(t)>0$ for $t \geq t_{1}$. Equation (1.1) yields

$$
\left(r x^{\prime}\right)^{\prime}(t)=-q_{0}(t) x\left(\tau_{0}(t)\right)-\sum_{i=1}^{n} q_{i}(t) x^{\beta_{i}}\left(\tau_{i}(t)\right)+e(t) \leq 0 .
$$

With a proof similar to that of [12, Theorem 3.1], we conclude that

$$
x(t)>0, \quad x^{\prime}(t)>0, \quad x^{\prime \prime}(t) \leq 0, \quad\left(r x^{\prime}\right)^{\prime}(t) \leq 0 .
$$

For $t \geq t_{1}$, define a function

$$
u(t):=\rho(t) \frac{r(t) x^{\prime}(t)}{x(\tau(t))}
$$

Then $u(t)>0$ for $t \geq t_{1}$. Differentiating (2.5), by virtue of (2.3) and (2.4), we have $x^{\prime}(\tau(t)) \geq$ $r(t) x^{\prime}(t) / r(\tau(t))$, and so

$$
\begin{aligned}
u^{\prime}(t)= & \frac{\rho^{\prime}(t)}{\rho(t)} u(t)-\rho(t) \frac{r(t) x^{\prime}(t)}{x^{2}(\tau(t))} x^{\prime}(\tau(t)) \tau^{\prime}(t)-\rho(t) \frac{q_{0}(t) x\left(\tau_{0}(t)\right)}{x(\tau(t))} \\
& -\rho(t) \frac{\sum_{i=1}^{n} q_{i}(t) x^{\beta_{i}}\left(\tau_{i}(t)\right)-e(t)}{x(\tau(t))} \\
\leq & \frac{\rho_{+}^{\prime}(t)}{\rho(t)} u(t)-\frac{\tau^{\prime}(t) u^{2}(t)}{\rho(t) r(\tau(t))}-\rho(t)\left[q_{0}(t)+\frac{\sum_{i=1}^{n} q_{i}(t) x^{\beta_{i}}\left(\tau_{i}(t)\right)-e(t)}{x(\tau(t))}\right] .
\end{aligned}
$$

Let $y:=x\left(\tau_{i}(t)\right)-1$. It follows from Lemma 2.1 that

$$
x^{\beta_{i}}\left(\tau_{i}(t)\right) \geq \beta_{i} x\left(\tau_{i}(t)\right)+1-\beta_{i} .
$$


Hence, we deduce that

$$
\begin{aligned}
\frac{\sum_{i=1}^{n} q_{i}(t) x^{\beta_{i}}\left(\tau_{i}(t)\right)-e(t)}{x(\tau(t))} & \geq \frac{\sum_{i=1}^{n} q_{i}(t)\left[\beta_{i} x\left(\tau_{i}(t)\right)+\left(1-\beta_{i}\right)\right]-e(t)}{x(\tau(t))} \\
& \geq \sum_{i=1}^{n} \beta_{i} q_{i}(t)+\frac{\sum_{i=1}^{n}\left(1-\beta_{i}\right) q_{i}(t)-e(t)}{x(\tau(t))} .
\end{aligned}
$$

By virtue of (2.4), there exists a constant $M>0$ such that

$$
x(t) \leq M t .
$$

Thus, by (2.8), we obtain

$$
\frac{\sum_{i=1}^{n} q_{i}(t) x^{\beta_{i}}\left(\tau_{i}(t)\right)-e(t)}{x(\tau(t))} \geq \sum_{i=1}^{n} \beta_{i} q_{i}(t)+\frac{\sum_{i=1}^{n}\left(1-\beta_{i}\right) q_{i}(t)-e(t)}{M \tau(t)} .
$$

Substitution of (2.9) into (2.6) implies that

$$
\begin{aligned}
u^{\prime}(t) & \leq \frac{\rho_{+}^{\prime}(t)}{\rho(t)} u(t)-\frac{\tau^{\prime}(t) u^{2}(t)}{\rho(t) r(\tau(t))}-\rho(t)\left(q_{0}(t)+\sum_{i=1}^{n} \beta_{i} q_{i}(t)+\frac{\sum_{i=1}^{n}\left(1-\beta_{i}\right) q_{i}(t)-e(t)}{M \tau(t)}\right) \\
& \leq \frac{r(\tau(t))\left(\rho_{+}^{\prime}(t)\right)^{2}}{4 \rho(t) \tau^{\prime}(t)}-\rho(t)\left(q_{0}(t)+\sum_{i=1}^{n} \beta_{i} q_{i}(t)+\frac{\sum_{i=1}^{n}\left(1-\beta_{i}\right) q_{i}(t)-e(t)}{M \tau(t)}\right) .
\end{aligned}
$$

Integrating the latter inequality from $t_{1}$ to $t$, we conclude that

$$
\int_{t_{1}}^{t}\left[\rho(s)\left(q_{0}(s)+\sum_{i=1}^{n} \beta_{i} q_{i}(s)+\frac{\sum_{i=1}^{n}\left(1-\beta_{i}\right) q_{i}(s)-e(s)}{M \tau(s)}\right)-\frac{r(\tau(s))\left(\rho_{+}^{\prime}(s)\right)^{2}}{4 \rho(s) \tau^{\prime}(s)}\right] \mathrm{d} s \leq u\left(t_{1}\right),
$$

which contradicts (2.2). This completes the proof.

On the basis of Theorem 2.2, we can obtain the following results due to condition (2.1).

Corollary 2.3 Assume that conditions (1.2) and (2.1) are satisfied. If there exists a function $\rho \in \mathrm{C}^{1}\left(\left[t_{0}, \infty\right),(0, \infty)\right)$ such that

$$
\limsup _{t \rightarrow \infty} \int_{t_{0}}^{t}\left[\rho(s)\left(q_{0}(s)+\sum_{i=1}^{n} \beta_{i} q_{i}(s)\right)-\frac{r(\tau(s))\left(\rho_{+}^{\prime}(s)\right)^{2}}{4 \rho(s) \tau^{\prime}(s)}\right] \mathrm{d} s=\infty,
$$

where $\rho_{+}^{\prime}$ is defined as in (1.4), then equation (1.1) is oscillatory.

Using $\rho(t)=t$ in Corollary 2.3, we can get the following criterion.

Corollary 2.4 Assume that conditions (1.2) and (2.1) are satisfied. If

$$
\limsup _{t \rightarrow \infty} \int_{t_{0}}^{t}\left[s\left(q_{0}(s)+\sum_{i=1}^{n} \beta_{i} q_{i}(s)\right)-\frac{r(\tau(s))}{4 s \tau^{\prime}(s)}\right] \mathrm{d} s=\infty
$$

then equation (1.1) is oscillatory. 
In what follows, we derive some oscillation criteria for (1.1) in the case where

$$
\int_{t_{0}}^{\infty} r^{-1}(t) \mathrm{d} t<\infty
$$

Theorem 2.5 Assume that conditions (2.1) and (2.10) are satisfied, and let $\tau_{j}(t) \leq t(j=$ $0,1,2, \ldots, n)$. Suppose also that there exists a function $\rho \in C^{1}\left(\left[t_{0}, \infty\right),(0, \infty)\right)$ such that $(2.2)$ holds. If

$$
\limsup _{t \rightarrow \infty} \int_{t_{0}}^{t}\left[\delta(s)\left(q_{0}(s)+\sum_{i=1}^{n} \beta_{i} q_{i}(s)+\frac{\sum_{i=1}^{n}\left(1-\beta_{i}\right) q_{i}(s)-e(s)}{K}\right)-\frac{1}{4 r(s) \delta(s)}\right] \mathrm{d} s=\infty
$$

holds for all constants $K>0$, where

$$
\delta(t):=\int_{t}^{\infty} r^{-1}(s) \mathrm{d} s
$$

then equation (1.1) is oscillatory.

Proof Assume that (1.1) has a nonoscillatory solution $x$. As above, we may assume that there is a $t_{1} \geq t_{0}$ such that $x(t)>0$ for $t \geq t_{1}$. By virtue of (1.1), we have (2.3). Then there exist two possible cases, i.e., $x^{\prime}(t)>0$ or

$$
x^{\prime}(t)<0 .
$$

Assume first that $x^{\prime}(t)>0$. Then we obtain (2.4). Proceeding as in the proof of Theorem 2.2, we can obtain a contradiction to (2.2). Suppose now that (2.13) holds. Define a new function $\omega$ by

$$
\omega(t):=\frac{r(t) x^{\prime}(t)}{x(t)}, \quad t \geq t_{1}
$$

Then $\omega(t)<0$ for $t \geq t_{1}$ and

$$
\begin{aligned}
\omega^{\prime}(t) & =\frac{\left(r x^{\prime}\right)^{\prime}(t) x(t)-r(t) x^{\prime}(t) x^{\prime}(t)}{x^{2}(t)} \\
& =\frac{-q_{0}(t) x\left(\tau_{0}(t)\right)-\sum_{i=1}^{n} q_{i}(t) x^{\beta_{i}}\left(\tau_{i}(t)\right)+e(t)}{x(t)}-\frac{\omega^{2}(t)}{r(t)} .
\end{aligned}
$$

On the other hand, we have (2.7), and so

$$
\begin{aligned}
\frac{\sum_{i=1}^{n} q_{i}(t) x^{\beta_{i}}\left(\tau_{i}(t)\right)-e(t)}{x(t)} & \geq \frac{\sum_{i=1}^{n} q_{i}(t)\left[\beta_{i} x\left(\tau_{i}(t)\right)+\left(1-\beta_{i}\right)\right]-e(t)}{x(t)} \\
& \geq \sum_{i=1}^{n} \beta_{i} q_{i}(t)+\frac{\sum_{i=1}^{n}\left(1-\beta_{i}\right) q_{i}(t)-e(t)}{x(t)}
\end{aligned}
$$


due to $\tau_{i}(t) \leq t(i=1,2, \ldots, n)$. By $(2.13)$, there exists a constant $K>0$ such that $x(t) \leq K$. Hence, by virtue of (2.16), we conclude that

$$
\frac{\sum_{i=1}^{n} q_{i}(t) x^{\beta_{i}}\left(\tau_{i}(t)\right)-e(t)}{x(t)} \geq \sum_{i=1}^{n} \beta_{i} q_{i}(t)+\frac{\sum_{i=1}^{n}\left(1-\beta_{i}\right) q_{i}(t)-e(t)}{K}
$$

It follows now from (2.15), (2.17), and $\tau_{0}(t) \leq t$ that

$$
\omega^{\prime}(t) \leq-q_{0}(t)-\sum_{i=1}^{n} \beta_{i} q_{i}(t)-\frac{\sum_{i=1}^{n}\left(1-\beta_{i}\right) q_{i}(t)-e(t)}{K}-\frac{\omega^{2}(t)}{r(t)} .
$$

Using the condition $\left(r x^{\prime}\right)^{\prime}(t) \leq 0$, we have, for $s \geq t$,

$$
x^{\prime}(s) \leq \frac{r(t) x^{\prime}(t)}{r(s)}
$$

Integrating the latter inequality from $t$ to $l$, we deduce that

$$
x(l)-x(t) \leq r(t) x^{\prime}(t) \int_{t}^{l} r^{-1}(s) \mathrm{d} s .
$$

Passing to the limit as $l \rightarrow \infty$, we have

$$
-x(t) \leq r(t) x^{\prime}(t) \delta(t)
$$

which yields

$$
\frac{r(t) x^{\prime}(t)}{x(t)} \delta(t) \geq-1
$$

i.e.,

$$
\omega(t) \delta(t) \geq-1
$$

Multiplying (2.18) by $\delta(t)$ and integrating the resulting inequality from $t_{1}$ to $t$, we obtain

$$
\begin{aligned}
& \omega(t) \delta(t)-\omega\left(t_{1}\right) \delta\left(t_{1}\right)+\int_{t_{1}}^{t} \delta(s)\left(q_{0}(s)+\sum_{i=1}^{n} \beta_{i} q_{i}(s)+\frac{\sum_{i=1}^{n}\left(1-\beta_{i}\right) q_{i}(s)-e(s)}{K}\right) \mathrm{d} s \\
& \quad+\int_{t_{1}}^{t} \frac{\omega(s)}{r(s)} \mathrm{d} s+\int_{t_{1}}^{t} \frac{\omega^{2}(s) \delta(s)}{r(s)} \mathrm{d} s \leq 0 .
\end{aligned}
$$

Hence, we derive from (2.19) that

$$
\begin{aligned}
& \int_{t_{1}}^{t}\left[\delta(s)\left(q_{0}(s)+\sum_{i=1}^{n} \beta_{i} q_{i}(s)+\frac{\sum_{i=1}^{n}\left(1-\beta_{i}\right) q_{i}(s)-e(s)}{K}\right)-\frac{1}{4 r(s) \delta(s)}\right] \mathrm{d} s \\
& \quad \leq 1+\omega\left(t_{1}\right) \delta\left(t_{1}\right),
\end{aligned}
$$

which contradicts (2.11). The proof is complete. 
Theorem 2.6 Assume that conditions (2.1) and (2.10) are satisfied, and let $\tau_{j}(t) \geq t(j=$ $0,1,2, \ldots, n)$. Suppose further that there exists a function $\rho \in C^{1}\left(\left[t_{0}, \infty\right),(0, \infty)\right)$ such that (2.2) holds. If, for all constants $K>0$,

$$
\begin{array}{r}
\limsup _{t \rightarrow \infty} \int_{t_{0}}^{t}\left[\delta(s)\left(q_{0}(s) \frac{\delta\left(\tau_{0}(s)\right)}{\delta(s)}+\sum_{i=1}^{n} \beta_{i} q_{i}(s) \frac{\delta\left(\tau_{i}(s)\right)}{\delta(s)}\right)\right. \\
\left.+\delta(s) \frac{\sum_{i=1}^{n}\left(1-\beta_{i}\right) q_{i}(s)-e(s)}{K}-\frac{1}{4 r(s) \delta(s)}\right] \mathrm{d} s=\infty
\end{array}
$$

where $\delta$ is as in (2.12), then equation (1.1) is oscillatory.

Proof Assume again that there exists a $t_{1} \geq t_{0}$ such that $x(t)>0$ for $t \geq t_{1}$. From (1.1), we have (2.3). Then there exist two possible cases, i.e., $x^{\prime}(t)>0$ or (2.13). Suppose that $x^{\prime}(t)>0$. Following the same lines as in Theorem 2.2, we can obtain a contradiction to (2.2). Assume now that (2.13) is satisfied. Define the function $\omega$ by (2.14). We have $\omega(t)<0$ for $t \geq t_{1}$ and (2.15). On the other hand, it has been established in Theorems 2.2 and 2.5 that (2.7) and (2.19) hold. By virtue of (2.19),

$$
\left(\frac{x}{\delta}\right)^{\prime}(t) \geq 0
$$

It follows from the latter inequality, $\tau_{j}(t) \geq t(j=0,1,2, \ldots, n)$, and (2.7) that

$$
\frac{x\left(\tau_{0}(t)\right)}{x(t)} \geq \frac{\delta\left(\tau_{0}(t)\right)}{\delta(t)}
$$

and

$$
\begin{aligned}
\frac{\sum_{i=1}^{n} q_{i}(t) x^{\beta_{i}}\left(\tau_{i}(t)\right)-e(t)}{x(t)} & \geq \frac{\sum_{i=1}^{n} q_{i}(t)\left[\beta_{i} x\left(\tau_{i}(t)\right)+\left(1-\beta_{i}\right)\right]-e(t)}{x(t)} \\
& \geq \sum_{i=1}^{n} \beta_{i} q_{i}(t) \frac{\delta\left(\tau_{i}(t)\right)}{\delta(t)}+\frac{\sum_{i=1}^{n}\left(1-\beta_{i}\right) q_{i}(t)-e(t)}{x(t)} .
\end{aligned}
$$

Since $x^{\prime}(t)<0$, there exists a constant $K>0$ such that $x(t) \leq K$. Hence, by (2.22), we conclude that

$$
\frac{\sum_{i=1}^{n} q_{i}(t) x^{\beta_{i}}\left(\tau_{i}(t)\right)-e(t)}{x(t)} \geq \sum_{i=1}^{n} \beta_{i} q_{i}(t) \frac{\delta\left(\tau_{i}(t)\right)}{\delta(t)}+\frac{\sum_{i=1}^{n}\left(1-\beta_{i}\right) q_{i}(t)-e(t)}{K} .
$$

Using (2.15), (2.21), and (2.23), we obtain

$$
\omega^{\prime}(t) \leq-q_{0}(t) \frac{\delta\left(\tau_{0}(t)\right)}{\delta(t)}-\sum_{i=1}^{n} \beta_{i} q_{i}(t) \frac{\delta\left(\tau_{i}(t)\right)}{\delta(t)}-\frac{\sum_{i=1}^{n}\left(1-\beta_{i}\right) q_{i}(t)-e(t)}{K}-\frac{\omega^{2}(t)}{r(t)}
$$

The remainder of the proof is similar to that of Theorem 2.5 and hence is omitted. This completes the proof.

Remark 2.7 From the proof of Theorems 2.5 and 2.6, one can obtain oscillation results for equation (1.1) with delayed and advanced arguments. The details are left to the reader. 


\section{Example}

The following example illustrates possible applications of the theoretical results presented in this paper.

Example 3.1 For $t \geq 1$, consider a second-order differential equation

$$
x^{\prime \prime}(t)+\frac{\gamma}{t^{2}} x\left(\frac{t}{2}\right)+\frac{1}{t^{2}}\left|x\left(\frac{t}{5}\right)\right| x\left(\frac{t}{5}\right)+\frac{1}{t^{2}} x^{3}\left(\frac{t}{40}\right)=-\frac{3}{t^{2}} \operatorname{sgn}(x(t))
$$

where $\gamma>0$ is a constant. Let $n=2, r(t)=1, q_{0}(t)=\gamma / t^{2}, q_{1}(t)=q_{2}(t)=1 / t^{2}, \tau_{0}(t)=t / 2$, $\tau_{1}(t)=t / 5, \tau(t)=\tau_{2}(t)=t / 40, e(t)=-3 / t^{2}, \beta_{1}=2$, and $\beta_{2}=3$. Then $\sum_{i=1}^{n}\left(1-\beta_{i}\right) q_{i}(t)-e(t)=$ 0 and

$$
\begin{aligned}
& \limsup _{t \rightarrow \infty} \int_{t_{0}}^{t}\left[s\left(q_{0}(s)+\sum_{i=1}^{n} \beta_{i} q_{i}(s)\right)-\frac{r(\tau(s))}{4 s \tau^{\prime}(s)}\right] \mathrm{d} s \\
& =(\gamma-5) \limsup _{t \rightarrow \infty} \int_{1}^{t} \frac{\mathrm{d} s}{s}=\infty, \quad \text { provided that } \gamma>5 .
\end{aligned}
$$

Hence, by Corollary 2.4, equation (3.1) is oscillatory for any $\gamma>5$.

Let $Q$ be defined as in Theorem 1.1. Then

$$
\begin{aligned}
Q(t) & =q_{0}(t)+\sum_{i=1}^{n} \beta_{i}\left[n\left(\beta_{i}-1\right)\right]^{\left(1-\beta_{i}\right) / \beta_{i}}\left(q_{i}(t)\right)^{1 / \beta_{i}}|e(t)|^{\left(\beta_{i}-1\right) / \beta_{i}} \\
& =\frac{1}{t^{2}}\left[\gamma+\sum_{i=1}^{2} \beta_{i}\left(\frac{2\left(\beta_{i}-1\right)}{3}\right)^{\left(1-\beta_{i}\right) / \beta_{i}}\right] \\
& =\frac{1}{t^{2}}\left[\gamma+2\left(\frac{3}{2}\right)^{1 / 2}+3\left(\frac{3}{4}\right)^{2 / 3}\right] \\
& <\frac{1}{t^{2}}(\gamma+2.45+2.477)=\frac{1}{t^{2}}(\gamma+4.927) .
\end{aligned}
$$

Using the latter inequality and $\rho(t)=t$ in (1.3), we observe that Theorem 1.1 cannot ensure oscillation of $(3.1)$ on the interval $(5,5.073]$. Therefore, Corollary 2.4 improves Theorem 1.1.

Remark 3.2 In this paper, several new oscillation criteria for equation (1.1) are obtained by using the Riccati substitution and Bernoulli's inequality. Employing inequalities different from those exploited in [12], we improve Theorem 1.1; see Example 3.1. Furthermore, Theorems 2.5 and 2.6 complement those by Zhong et al. [12] since our results can be applied to the case where (2.10) holds. 


\section{Author details}

${ }^{1}$ School of Informatics, Linyi University, Linyi, Shandong 276005, P.R. China. ${ }^{2}$ LinDa Institute of Shandong Provincial Key Laboratory of Network Based Intelligent Computing, Linyi University, Linyi, Shandong 276005, P.R. China. ${ }^{3}$ Ramanujan Institute for Advanced Study in Mathematics, University of Madras, Chennai, 600 005, India.

\section{Acknowledgements}

The authors express their sincere gratitude to the editors and anonymous referees for the careful reading of the original manuscript and useful comments that helped to improve the presentation of the results and accentuate important details. This research is supported by the AMEP of Linyi University, P.R. China.

\section{Received: 12 August 2014 Accepted: 18 November 2014 Published: 12 Dec 2014}

\section{References}

1. Hale, JK: Theory of Functional Differential Equations. Springer, New York (1977)

2. Agarwal, RP, Anderson, DR, Zafer, A: Interval oscillation criteria for second-order forced delay dynamic equations with mixed nonlinearities. Comput. Math. Appl. 59, 977-993 (2010)

3. Agarwal, RP, Grace, SR, O'Regan, D: Oscillation Theory for Difference and Functional Differential Equations. Kluwer Academic, Dordrecht (2000)

4. Agarwal, RP, Grace, SR, O’Regan, D: Oscillation Theory for Second Order Linear, Half-Linear, Superlinear and Sublinear Dynamic Equations. Kluwer Academic, Dordrecht (2002)

5. Agarwal, RP, Grace, SR, O'Regan, D: Oscillation criteria for certain $n$th order differential equations with deviating arguments. J. Math. Anal. Appl. 262, 601-622 (2001)

6. Agarwal, RP, Grace, SR, O'Regan, D: The oscillation of certain higher-order functional differential equations. Math. Comput. Model. 37, 705-728 (2003)

7. Agarwal, RP, Zafer, A: Oscillation criteria for second-order forced dynamic equations with mixed nonlinearities. Adv. Differ. Equ. 2009, 938706 (2009)

8. Hassan, TS, Erbe, L, Peterson, A: Forced oscillation of second order differential equations with mixed nonlinearities. Acta Math. Sci. 31, 613-626 (2011)

9. Li, W-T, Cheng, SS: An oscillation criterion for nonhomogeneous half-linear differential equations. Appl. Math. Lett. 15 259-263 (2002)

10. Sun, YG, Wong, JSW: Oscillation criteria for second order forced ordinary differential equations with mixed nonlinearities. J. Math. Anal. Appl. 334, 549-560 (2007)

11. Zheng, ZW, Wang, $X$, Han, HM: Oscillation criteria for forced second order differential equations with mixed nonlinearities. Appl. Math. Lett. 22, 1096-1101 (2009)

12. Zhong, J, Ouyang, Z, Zou, S: An oscillation theorem for a class of second-order forced neutral delay differential equations with mixed nonlinearities. Appl. Math. Lett. 24, 1449-1454 (2011)

\section{Submit your manuscript to a SpringerOpen ${ }^{\odot}$ journal and benefit from:}

- Convenient online submission

- Rigorous peer review

- Immediate publication on acceptance

Open access: articles freely available online

- High visibility within the field

- Retaining the copyright to your article 